\title{
Review
}

\section{Cholecystectomy in cirrhotic patients - how safe is it?}

\author{
Petrişor Banu ${ }^{1,2}$, Vlad D. Constantin ${ }^{1,2}$, Florian Popa ${ }^{1,2}$, Ion Motofei ${ }^{1,2}$, \\ Cristian Bălălău ${ }^{1,2}$ \\ ${ }^{1}$ Carol Davila University, Department of Surgery, Bucharest, Romania \\ ${ }^{2}$ St. Pantelimon Hospital, Department of Surgery, Bucharest, Romania
}

\begin{abstract}
Liver cirrhosis is a major health problem worldwide with a prevalence that varies greatly from one geographical area to another.

Besides the risk factors common to the general population to develop gallstone disease such as advanced age, female sex or positive family history of gallstones, in patients with liver cirrhosis there are additional risk factors that contribute to the occurrence of gallstones. They are more frequent in patients with a longer duration of the disease and in Child B and C stages. Gallstones disease occurs three times more frequently in patients with liver cirrhosis than in noncirrhotic patients.
\end{abstract}

Surgery is required if symptoms or complications related to the presence of gallstones occur and a thorough preoperative evaluation and optimization of patient's condition is necessary prior to surgery.

The procedure of choice in these situations is laparoscopic cholecystectomy. The technique has some particularities resulting from local anatomical changes and conversion to open technique remains low and morbidity and mortality rates are within acceptable limits.

Keywords: cholecystectomy, gallstones, cirrhosis, safety 


\section{Introduction}

Liver cirrhosis is a major health problem worldwide whose main etiological factors are represented by alcohol consumption and hepatitis virus infections. At the same time, the disease is three times more frequently associated with gallstone disease.

If there are no symptoms related to the presence of gallstones close monitoring is recommended but surgery becomes necessary if symptoms or complications occur.

Surgery in these patients is encumbered by a higher morbidity and mortality rates than in noncirrhotic patients and requires optimization of patient's condition prior to the procedure and also has some specific technical approaches.

They are imposed both by the systemic effects caused by cirrhosis and by local anatomical changes.

Liver cirrhosis is a major health problem worldwide. Its prevalence varies greatly from one geographical area to another and etiological factors are closely linked with the socioeconomic status and cultural background.

These differences are multifactorial and they result from the fact that on the one hand the main etiological factors of the disease are represented by alcohol consumption and hepatitis virus infections and, on the other hand, diagnosis of the disease and official reports are made differently from one country to another. In USA it is estimated that cirrhosis has an age standardized mortality rate of 11,3 per 100,000 and in Europe between 1,7 and 71,2 per 100,000 for Iceland and for Moldova, respectively (1).

The true prevalence of the disease is very difficult to estimate due to the fact that apart from cases diagnosed and treated, there is an unquantifiable percentage of cases with unknown diagnosis whose death occurs from a complication of the disease (2).
Liver cirrhosis is the final evolutionary stage of pathological changes of the liver induced by chronic inflammatory processes.

The main characteristic feature of cirrhosis is the profound alteration in liver architecture by regenerative nodules which are surrounded by fibrous connective tissue as a response to hepatocyte necrosis.

These changes have consequences in hepatic blood flow and on its functional capacity.

As the disease progresses, these disorders became clinically expressed by signs of portal hypertension and liver failure.

\section{Gallstone disease in cirrhotic patients}

In patients with liver cirrhosis gallstones occur in a percentage of 23 to 79 which is three times more frequent then in non-cirrhotic patients (3).

The risk of developing gallstones increases in these patients with duration of the disease and its evolution stage and have a higher incidence in Child B and C stages (4).

In terms of epidemiology, gallstone disease is a leading cause for hospital admissions and it has a variable prevalence from one geographic region to another with $10-15 \%$ in USA and between 9 and $21 \%$ in Europe, figures recorded on the basis of ultrasonographic and necroptic data. These differences are correlated with the type of diet and socioeconomic level and the disease is less prevalent in the developing populations $(5,6)$.

Besides the risk factors common to the general population to develop gallstone disease such as advanced age, female sex or positive family history of gallstones, in patients with liver cirrhosis there are additional risk factors that contribute to the occurrence of gallstones. This is due to changes belonging both to the gallblader and to the composition of bile (7).

In most cases, patients with liver cirrhosis develop black pigment stones. This is due an 
increased concentration of unconjugated bilirubin or free ionized $\mathrm{Ca}^{2+}$ in the bile causing a supersaturation in calcium bilirubinate.

Increasing the proportion of $\mathrm{Ca}^{2+}$ is due to mucin hypersecretion leading to defective acidification of the bile and precipitation of calcium.

High concentration of unconjugated bilirubin results from increased hemolysis by hypersplenism and Kupffer cell destruction and decreasing in solubilization of the unconjugated bilirubin in bile (8).

Disorders in vesicular kinetics consist of hypomotility induced by wall edema and hormonal changes in the context of cirrhosis. Relaxing peptides such as VIP, somatostatin and glucagon have increased levels in plasma due to their less degradation in liver which combined with a resistance of the CCK receptors lead to gallbladder hypomotility and bile stasis $(9,10)$.

Regarding the etiology of liver cirrhosis there is a higher lithogenetic risk in $\mathrm{HCV}$ infection, non-alcoholic liver disease and alcohol-related liver cirrhosis (11-13).

\section{Discussion}

In the general population $20 \%$ of gallstones will develop symptoms and complications but in cirrhotic patients cholecystectomy is more often performed although in these patients symptoms related to gallstone disease have also a low incidence. It seems to be correlated with more precocious diagnosis of lithiasis occasioned by the regular follow up for the underlying disease $(14,15)$.

In liver cirrhosis gallstone related symptoms occur more frequent in female patients, advanced age, viral etiology, in cases with positive family history of gallstones and a longer duration of disease. On the contrary, male gender and alcoholic etiology are correlated with a rare occurrence of symptoms (16).
In cirrhotic patients as in the general population close monitoring is recommended if there are no symptoms related to the presence of gallstones but it requires surgery if symptoms or complications occur.

Practicing surgery in these patients is encumbered by a certain restraint due to their fragile background and risk of decompensation that can be precipitated by surgery. As the disease progresses a plurality of systemic disfunctions are associated with the liver one and thus cirrhosis becomes a systemic disease.

Cirrhotic patients have a hyperdynamic circulatory syndrome manifested by increasing cardiac output and decreased peripheral resistance. It is actually a state of heart failure hidden by decreasing afterload which compensates ventricular filling shortfall but it becomes manifested in conditions of a physiological or pharmacological stress revealing the so-called "cirrhotic cardiomyopathy" $(17,18)$.

Regarding the respiratory function, patients with liver cirrhosis have a degree of hypoxemia caused by ascending the diaphragm due to increased abdominal pressure in the presence of ascites. The risk of pulmonary atelectasis is correlated with the presence of ascites and hydrothorax. The latter can occur by two mechanisms: increased venous pressure due to salt retention and a decreased oncotic pressure by protein deficiency or a direct passage of ascites fluid to pleural space through diaphragmatic small channels (19).

Hepato-pulmonary syndrome, as severe functional decompensation of the two organs, is characterized by the triad: liver failure, severe hypoxemia $(\mathrm{PaO} 2<70 \mathrm{mmHg})$ and pulmonary shunts opening and it has a very high with mortality (20).

Hepato-renal syndrome is a severe renal impairment due to an important reduction in glomerular filtrate rate given by vasoconstriction which can be triggered by a lot of factors including bacterial infections. What distinguishes this syndrome from acute tubular necrosis is the absence of histological lesions (21). 
To all the above, if we add coagulation disorders, deficiency in protein synthesis, immune dysfunctions and the fact that these deficiencies increase with progression of the cirrhosis, it becomes obvious why practicing surgery in these patients requires a thorough preoperative evaluation and optimization of patient's condition prior to surgery.

Complications related to cholecystectomy in these patients are blood loss, postoperative liver failure and sepsis that may cause high rates of mortality and morbidity (22).

Laparoscopic cholecystectomy has become the gold standard in the treatment of benign diseases of the gallbladder and expanded its indications in patients with liver cirrhosis due firstly that is less traumatic and has lower mortality and morbidity associated with. These arise from the fact that the procedure does not require a large opening of the peritoneum and there is a lower risk of ascitic fluid leak and sepsis (23).

Its benefits are primarily given by patient's comfort which has a shorter postoperative stay in hospital, reduced wound complications and an earlier socio-professional reintegration. Most studies consider patients with compensated cirrhosis Child A and B class and there are few reports on the Child $\mathrm{C}$ class cirrhosis. In the latter ones, cholecystectomy is indicated only if medical management fails and cholecystitis becomes a life-threatening condition (24, 25).

In order to minimize intra- and postoperative risks related to laparoscopic cholecystectomy one should consider some particular aspects.

Port-site bleeding risk can be reduced by placing the trocars in such a manner as to avoid dilated veins of the abdominal wall and umbilical vein, preferably by open method of peritoneal access and infraumbilical placement of camera trocar.

During the procedure it is recommended to keep a lower flow of carbon dioxide and a reduced pressure of pneumoperitoneum or even gasless pneumoperitoneum as a protective effect to ischemia reperfusion which may aggravate the damage to hepatic function (26).

In liver cirrhosis gallbladder wall becomes stiff and more friable which creates difficulties in its handling and identification elements of the hilum with risk of parietal bleeding and thus precluding excessive traction on the gallbladder.

Liver is hard and fibrotic with compensatory hypertrophy making more difficult its retraction and Calot's triangle exposure sometimes requiring one additional 5-mm port and using of fundus first technique (27).

Portal hypertension can cause bleeding from the gallbladder bed which can be difficult to control. In such situations it can be an option to leave the posterior wall intact with the liver (laparoscopic subtotal cholecystectomy I) and the remnant mucosa being removed by mucosectomy or by electrofulguration (28).

The second version of laparoscopic subtotal cholecystectomy consists of circumferentially dividing of the infundibulum as close as possible to the junction of the gallbladder and cystic duct and it can be used when there is an uncertain anatomy in the hilum but one must consider the possibility of retained stone in the stump (29).

Laparoscopic subtotal cholecystectomy III is a version that combines the previous two and it can be chosen when both hilum and gallbladder are at highrisk.

Neovascularization and vascularized adhesions can be the source of difficult to control bleeding requiring mechanical compression or special means for hemostasis such as ultrasonic shears, argon beam coagulation and hemostasis agents (30).

For laparoscopic cholecystectomy, in cirrhosis overall complications occur in $17,6 \%$ of cases with $5,9 \%$ infections and $0,8 \%$ mortality rate (31). 
The conversion rate is around $6 \%$ and it is mainly due to the impossibility to control bleeding or inability to recognize the anatomy properly (32).

Complications are more common in these patients compared to those without cirrhosis and especially for advanced stages of the disease, Child B and C. A higher morbidity is correlated with the presence of ascites (33).

Gallbladder bed, cystic pedicle or port-site may be the sources of persistent bleeding that can require blood transfusion. Postoperative infection can manifest as abdominal collection, wound infection or pulmonary infection.

Surgical act may worsen cirrhosis causing liver failure, encephalopathy and worsening of ascites (34).

By comparison, in patients with liver cirrhosis, open surgery has a longer operative and anesthetic time, it is accompanied by a higher blood loss and its morbidity is higher than non-cirrhotic patients by deterioration of liver function, pulmonary complications, wound infections and postoperative hernia. Complications occur in $47,7 \%$ of cases and infection in $19,9 \%$. Mortality can reach $2 \%(31,35$, 36).

\section{Conclusions}

In patients with liver cirrhosis laparoscopic cholecystectomy is the preferable procedure for gallstone disease. The technique has some particularities resulting from local anatomical changes and particular solutions can be adopted.

In experienced hands, conversion to open technique remains low and morbidity and mortality rates are within acceptable limits.

The best results are obtained in Child A and B stages.

\section{References}

1. McGillicuddy JW, Villar JJ, Rohan VS, Bazaz S, Taber DJ, Pilch NA, Baliga PK, Chavin KD. Is cirrhosis a contraindication to laparoscopic cholecystectomy? Am Surg. 2015; 81(1): 52-5. PMID: 25569066

2. Machado NO. Laparoscopic cholecystectomy in cirrhotics. JSLS. 2012; 16(3): 392-400. PMID: 23318064

https://doi.org/10.4293/108680812X13462882736 $\underline{493}$

3. Del Olmo Leale I, Moraglia E, Bottino G, Rachef M, Dova L, Cariati A, De Negri A, Diviacco P, Andorno E. Role of Liver Transplantation in BilioVascular Liver Injury After Cholecystectomy. Transplant Proc. 2016; 48(2): 370-6. PMID: 27109958

https://doi.org/10.1016/j.transproceed.2015.12.035

4. Xiao L, Li JW, Zheng SG. Totally laparoscopic ALPPS in the treatment of cirrhotic hepatocellular carcinoma. Surg Endosc. 2015; 29(9): 2800-1. PMID: 25515978 https://doi.org/10.1007/s00464014-4000-1

5. Tazuma S. Gallstone disease: Epidemiology, pathogenesis, and classification of biliary stones (common bile duct and intrahepatic). Best Pract Res Clin Gastroenterol. 2006; 20(6): 1075-83. PMID: 17127189

\section{https://doi.org/10.1016/j.bpg.2006.05.009}

6. Cheng Y, Xiong XZ, Wu SJ, Lin YX, Cheng NS. Laparoscopic vs. open cholecystectomy for cirrhotic patients: a systematic review and metaanalysis. Hepatogastroenterology. 2012; 59(118): 1727-34. PMID: 22193435

7. Zhang Y, Liu D, Ma Q, Dang C, Wei W, Chen W. Factors influencing the prevalence of gallstones in liver cirrhosis. J Gastroenterol Hepatol. 2006; 21: 1455-1458. PMID: 16911692 https://doi.org/10.1111/j.1440-1746.2006.04465.x

8. Lledó JB, Ibañez JC, Mayor LG, Juan MB. Laparoscopic cholecystectomy and liver cirrhosis. Surg Laparosc Endosc Percutan Tech. 2011; 21(6): 391-5. PMID: 22146159

https://doi.org/10.1097/SLE.0b013e31823b5096 
9. El Nakeeb A, Askar W, El Lithy R, Farid M. Clipless laparoscopic cholecystectomy using the Harmonic scalpel for cirrhotic patients: a prospective randomized study. Surg Endosc. 2010; 24(10): 2536-41. PMID: 20376490 https://doi.org/10.1007/s00464-010-0999-9

10. Rotellar F, Bueno Á, Benito A, Martí-Cruchaga P, Zozaya G, Pedano N, Pardo F. Totally laparoscopic resection of solid hepatic lesions: analysis of a single-centre series of 71 cases. Cir Esp. 2012; 90(9): 569-75. PMID: 22841612 https://doi.org/10.1016/j.ciresp.2012.05.020

11. Chang TS, Lo SK, Shyr HY, Fang JT, Lee WC, Tai DI, Sheen IS, Lin DY, Chu CM, Liaw YF. Hepatitis $\mathrm{C}$ virus infection facilitates gallstone formation. J Gastroenterol Hepatol. 2005; 20(9): 1416-21. PMID: 16105130

https://doi.org/10.1111/j.1440-1746.2005.03915.x

12. Ara C, Ozdemir F, Ateş M, Ozgör D, Kutlutürk K. Partial cholecystectomy: a technique that makes hilar dissection easier in recipient hepatectomy. Transplant Proc. 2014; 46(1): 216-8. PMID: 24507054

https://doi.org/10.1016/j.transproceed.2013.05.016

13. Shaikh AR, Muneer A. Laparoscopic cholecystectomy in cirrhotic patients. JSLS. 2009; 13(4): 592-6. PMID: 20202403

https://doi.org/10.4293/108680809X12589999537 959

14. Machado NO. Laparoscopic cholecystectomy in cirrhotics. JSLS. 2012; 16(3): 392-400. PMID: 23318064

https://doi.org/10.4293/108680812X1346288273 $\underline{6493}$

15. Acalovschi M. Gallstones in patients with liver cirrhosis: Incidence, etiology, clinical and therapeutical aspects. World J Gastroenterol. 2014; 20(23): 7277-85. PMID: 24966598 https://doi.org/10.3748/wjg.v20.i23.7277

16. Franceschet I, Zanetto A, Ferrarese A, Burra P, Senzolo M. Therapeutic approaches for portal biliopathy: A systematic review. World $J$ Gastroenterol. 2016; 22(45): 9909-9920. PMID: 28018098

https://doi.org/10.3748/wjg.v22.i45.9909

17. Rizk HA, Saleem AA. Laparoscopic cholecystectomy for patients with cholelithiasis and liver cirrhosis. J Egypt Soc Parasitol. 2008; 38(2): 609-20. PMID: 18853632

18. Quillin RC 3rd, Burns JM, Pineda JA, Hanseman D, Rudich SM, Edwards MJ, Tevar AD. Laparoscopic cholecystectomy in the cirrhotic patient: predictors of outcome. Surgery. 2013; 153(5): 634-40. PMID: 23305593

https://doi.org/10.1016/j.surg.2012.11.012

19. Ji W, Li LT, Li JS. Role of laparoscopic subtotal cholecystectomy in the treatment of complicated cholecystitis. Hepatobiliary Pancreat Dis Int. 2006; 5(4): 584-9. PMID: 17085347

20. Chmielecki DK, Hagopian EJ, Kuo YH, Kuo YL, Davis JM. Laparoscopic cholecystectomy is the preferred approach in cirrhosis: a nationwide, population-based study. HPB (Oxford). 2012; 14(12): 848-53. PMID: 23134187

https://doi.org/10.1111/j.1477-2574.2012.00562.X

21. Lledó JB, Ibañez JC, Mayor LG, Juan MB. Laparoscopic cholecystectomy and liver cirrhosis. Surg Laparosc Endosc Percutan Tech. 2011; 21(6): 391-5. PMID: 22146159 https://doi.org/10.1097/SLE.0b013e31823b5096

22. Bessa SS, Abdel-Razek AH, Sharaan MA, Bassiouni AE, El-Khishen MA, El-Kayal el-SA. Laparoscopic cholecystectomy in cirrhotics: a prospective randomized study comparing the conventional diathermy and the harmonic scalpel for gallbladder dissection. J Laparoendosc $A d v$ Surg Tech A. 2011; 21(1): 1-5. PMID: 21166564 https://doi.org/10.1089/lap.2010.0255

23. Nicoll A. Surgical risk in patients with cirrhosis. $J$ Gastroenterol Hepatol. 2012; 27(10): 1569-75. PMID: 22694313 https://doi.org/10.1111/j.14401746.2012.07205.x 
24. Dionigi R, Dominioni L, Benevento A, Giudice G, Cuffari S, Bordone N, Caravati F, Carcano G, Gennari R. Effects of surgical trauma of laparoscopic vs. open cholecystectomy. Hepatogastroenterology. 1994; 41(5): 471-6. PMID: 7851857

25. de Goede B, Klitsie PJ, Hagen SM, van Kempen BJ, Spronk S, Metselaar HJ, Lange JF, Kazemier G. Meta-analysis of laparoscopic versus open cholecystectomy for patients with liver cirrhosis and symptomatic cholecystolithiasis. Br J Surg. 2013; 100(2): 209-16. PMID: 23034741 https://doi.org/10.1002/bjs.8911

26. Leandros E, Albanopoulos K, Tsigris C, Archontovasilis F, Panoussopoulos SG, Skalistira M, Bramis C, Konstandoulakis MM, Giannopoulos A. Laparoscopic cholecystectomy in cirrhotic patients with symptomatic gallstone disease. ANZ J Surg. 2008; 78(5): 363-5. PMID: 18380734 https://doi.org/10.1111/j.14452197.2008.04478.x

27. Machado NO. Laparoscopic Cholecystectomy in Cirrhotics. JSLS : JSLS. 2012; 16(3): 392-400. PMID: 23318064

https://doi.org/10.4293/108680812X13462882736 $\underline{493}$

28. Palanivelu C, Rajan PS, Jani K, Shetty AR, Sendhilkumar K, Senthilnathan P, Parthasarthi R. Laparoscopic cholecystectomy in cirrhotic patients: the role of subtotal cholecystectomy and its variants. J Am Coll Surg. 2006; 203(2): 145-51. PMID: 16864026

https://doi.org/10.1016/j.jamcollsurg.2006.04.019

29. Bessa SS, Abdel-Razek AH, Sharaan MA, Bassiouni AE, El-Khishen MA, El-Kayal el-SA. Laparoscopic cholecystectomy in cirrhotics: a prospective randomized study comparing the conventional diathermy and the harmonic scalpel for gallbladder dissection. $J$ Laparoendosc Adv Surg Tech A. 2011; 21(1): 1-5. PMID: 21166564 https://doi.org/10.1089/lap.2010.0255
30. Ashfaq A, Ahmadieh K, Shah AA, Chapital AB, Harold KL, Johnson DJ. The difficult gall bladder: Outcomes following laparoscopic cholecystectomy and the need for open conversion. Am J Surg. 2016; 212(6): 1261-1264. PMID: 28340928 https://doi.org/10.1016/j.amjsurg.2016.09.024

31. Lin XK, Wu DZ, Cai JL, Chen CD, Wang KL. Transumbilical Single-Incision Laparoscopic Surgery in Children with Conventional Instruments: Our Early Experience. $J$ Laparoendosc Adv Surg Tech A. 2016; 26(11): 938-941. PMID: 27676654 https://doi.org/10.1089/lap.2016.0138

32. Sheikh MR, Osman H, Cheek S, Hunter S, Jeyarajah DR. T2 Gallbladder Cancer-Aggressive Therapy Is Warranted. Am Surg. 2016; 82(6): 51821. PMID: 27305883

33. Puggioni A, Wong LL. A metaanalysis of laparoscopic cholecystectomy in patients with cirrhosis. J Am Coll Surg. 2003; 197(6): 921-6. PMID: 14644279

https://doi.org/10.1016/j.jamcollsurg.2003.08.011

34. Akhter MS, Verma R, Madhukar KP, Vaishampayan AR, Unadkat PC. Incidence of surgical site infection in postoperative patients at a tertiary care centre in India. J Wound Care. 2016; 25(4): 210-2, 214-7. PMID: 27064370 https://doi.org/10.12968/jowc.2016.25.4.210

35. Poggio JL, Rowland CM, Gores GJ, Nagorney DM, Danohre JA. A comparison of laproscopic and open cholecystectomy in patients with compensated cirrhosis and symptomatic gallstones disease. Surgery 2000; 127: 405-11. PMID: 10776431

https://doi.org/10.1067/msy.2000.104114

36. Perera ML, Gnaneswaran N, Roberts MJ, Giles M, Liew D, Ritchie P, Chan ST. The 'four-hour target' and the impact on Australian metropolitan acute surgical services. ANZ J Surg. 2016; 86(1-2): 74-8. PMID: 26096442 https://doi.org/10.1111/ans.13186 